\title{
Traumatic pneumorrhachis: a rare entity of trauma
}

\author{
Serhat Akay • Basak Bayram
}

Received: 29 December 2007 / Accepted: 17 January 2008/Published online: 15 March 2008

(C) Springer-Verlag London Ltd 2008

\section{Introduction}

A 35-year-old man was transferred comatose to a level-1 trauma center after being struck by a train. His vital signs were stable upon arrival. His physical examination revealed a Glasgow Coma Scale score of 3, extensive scalp laceration, and raccoon eyes, with normal findings for other systems. He was subsequently intubated, and computed tomography (CT) of the head and cervical spine as well as thorax and abdomen was performed.

Cranial CT showed dislocated fracture of the left parietal bone, traumatic subarachnoidal hemorrhage, and pneumocephalus; CT of the cervical spine showed air in the spinal canal. Thoracic and abdominal CTs were normal. His hemoglobin levels were stable during follow-up. After consultation with neurosurgery, he was transferred to the intensive care unit, where he remained comatose in the following hours and died the next day as a result of severe head trauma.

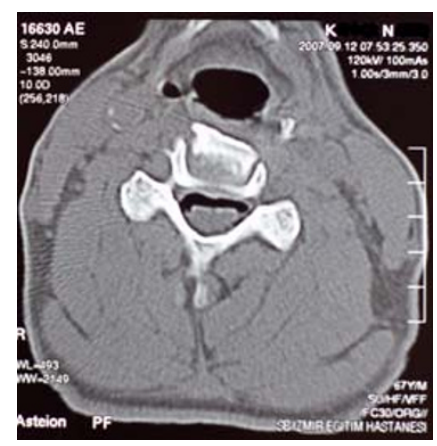

S. Akay $(\bowtie)$

Department of Emergency Medicine,

Izmir Research and Training Hospital,

Bozyaka,

Izmir, Turkey

e-mail: howls_Castle@mynet.com

\section{B. Bayram}

Department of Emergency Medicine,

Dokuz Eylul University Department of Emergency Medicine, Izmir, Turkey

e-mail: basakdr@yahoo.com

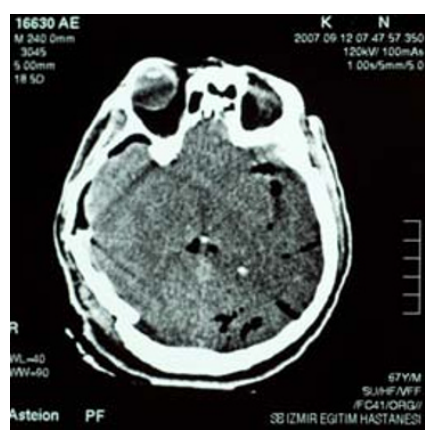

Pneumorrhachis (PR) is an exceptional radiological finding consistent with air in the spinal canal. Although the main cause is trauma, others are described in the literature and can be classified as traumatic and non-traumatic [1]. Traumatic causes are rare, and PR with trauma is associated with extreme trauma. It is an incidental finding and usually clinically nonspecific. PR in the presence of trauma is a marker of severe injury. Another classification can be described as epidural (intraspinal, epidural air) and intradural (intraspinal air within subdural or subarachnoid space) PR [2]. Differentiation can be difficult in some cases. Diagnosis is usually made by $\mathrm{CT}$, but plain radiographs can detect large volumes of intraspinal air. In our case, air that entered the body via the cranial fracture was forced caudally into the spinal canal through the foramen magna as a result of increased intracranial pressure. Because of its rarity, management of PR is controversial and usually conservative. The causes of PR need to be treated on an individual basis, while PR most often reabsorbs spontaneously.

\section{References}

1. Goh BK, Yeo AW (2005) Traumatic pneumorrhachis. J Trauma 58 (4):875-879

2. Oertel MF, Korinth MC, Reinges MH et al (2006) Pathogenesis, diagnosis and management of pneumorrhachis. Eur Spine J 15 Suppl 17:636-643 